International Journal of Molecular Medicine and Advance Sciences 6 (4): 49-53, 2010

ISSN: $1813-176 \mathrm{X}$

(C) Medwell Journals, 2010

\title{
Wound Healing Activity of Total Sulfated Glycosaminoglycan (GAG) from Stichopus vastus and Stichopus hermanni integumental Tissue in Rats
}

\author{
${ }^{1}$ Siti Fathiah Masre, ${ }^{2}$ George W. Yip, ${ }^{3}$ K.N.S Sirajudeen and ${ }^{1}$ Farid Che Ghazali \\ ${ }^{1}$ Biomedical Sciences Programme, \\ School of Health Sciences, Universiti of Sains Malaysia, Kubang Kerian, Malaysia \\ ${ }^{2}$ Department of Anatomy, Yong Loo Lin School of Medicine, \\ National University of Singapore, 117597, Singapore \\ ${ }^{3}$ Department of Chemical Pathology, School of Medical Sciences, \\ Universiti Sains Malaysia, Kubang Kerian, Malaysia
}

\begin{abstract}
Sea cucumbers have long been purported as a source of traditional medicine including wound healing due to the presence of sulfated Glycosaminoglycans (GAGs). Total sulfated Glycosaminoglycan (GAG) from sea cucumber Stichopus hermanni and Stichopus vastus integumental tissue were investigated for evaluation of wound healing potential in rats. Three groups of female Sprague-Dawley rats each consist of 6 animals were assigned. Normal saline was applied as a control to group 1 rats while group 2 and group 3 rats were treated topically with total sulfated GAG from both sea cucumber species' integumental tissue to $6 \mathrm{~mm}$ diameter of full thickness wound from day $0-12$. The effects on the contraction rate of wound healing were assessed. Wounds treated with total sulfated GAG from Stichopus hermanni and Stichopus vastus integumental tissue showed significantly $(\mathrm{p}<0.05)$ improve wound contraction rate compared to wounds in control group. These results seems to suggest the beneficial effects of total sulfated GAG particularly from the integument body wall of sea cucumber for the positive enhancement of wound healing process in rats model.
\end{abstract}

Key words: Sea cucumber, sulfated glycosaminoglycans, wound healing, rats, GAG, Sprague-Dawley

\section{INTRODUCTION}

For over many centuries, sea cucumbers have been a food delicacy and medicines for Asians. Primarily, sea cucumber has been collected for food but extensive research on sea cucumber has explored it as a source of medicinal components. Sea cucumbers have good therapeutic value and potential to be commercialized in the field of modern treatment and cosmetics. Sea cucumber has been nominated as poly-anion rich food due to the presence of glycosaminoglycans that have influence in many physiologically active function including wound healing activities (Liu et al., 2002).

Glycosaminoglycans (GAGs) which are sometimes known as mucopolysaccharides (Neha and Ricardo, 2008) are large complex carbohydrate molecules that interact with a wide range of proteins involved in physiological and pathological processes (Jackson et al., 1991; Casu and Lindahl, 2001). There are two types of GAGs, sulfated GAGs and non-sulfated GAGs (Neha and Ricardo, 2008). Sulfated GAGs include chondroitin sulfate, dermatan sulfate, keratan sulfate, heparan sulfate and heparin (Kimata et al., 2007). Studies have shown that sulfated GAGs such as chondroitin sulfate and heparan sulfate can implicate in the positive wound healing processes (Zou et al., 2004; Annika et al., 2007).

Wound healing is a complex pathophysiological phenomenon with dynamic cascade of events initiated by an injury (Inkinen, 2003). Wound healing disorders present a serious clinical problem and are likely to increase since they are associated with diseases such as diabetes, hypertension and obesity. Moreover, increasing life expectancies will cause more people to face such disorders and further aggravate this medical problem (Frank and Kampfer, 2005). Varieties of approaches for new treatment have become available for patients with both acute and chronic wounds over the past decade (Bello and Phillips, 2000). Therefore, this study was undertaken to determine the wound healing activity of the total sulfated GAG extracted from the integumental tissue of S. hermanni and $S$. vastus in experimental wounds in rats.

Corresponding Author: Farid Cheghazali, Biomedical Sciences Programme, School of Health Sciences, University of Sains Malaysia, Kubang Kerian, Malaysia 


\section{MATERIALS AND METHODS}

Sea cucumbers: Adult sea cucumbers $S$. hermanni and S. vastus (Echinodermata-Holothuroidea) (each $\mathrm{n}=5$ ) were freshly harvested from the Perhentian island coast around area 5-10 m deep in May, 2009 and were dropped in Marine Finfish Production and Research Center (MAFPREC), Tanjung Demong Terengganu, Malaysia. The taxonomies were confirmed by the fishery officer, Abdul Razak Hamzah from MAFPREC and specimens were deposited at the School of Health Sciences, USM Centre for Sea Cucumber Research.

Extraction of total Glycosaminoglycan (GAG) from sea cucumbers: The sea cucumbers were desalted by gently washed using distilled water. The integumental tissue of S. hermanni and S. vastus was dissected and $20 \mathrm{mg}$ was measured to extract the GAGs. GAGs extraction from sea cucumber was carried out by the method of Ledin et al. (2004) adapted from Staatz et al. (2001). Finally, the supernatant which contained the extracted GAGs was collected in a $2.0 \mathrm{~mL}$ microcentifuge tube (Axygen, Union City, California) and stored at $-20^{\circ} \mathrm{C}$ until used.

Preparation of total sulfated Glycosaminoglycan (GAG) for wound healing study: Total sulfated GAG content of the integument body wall part from sea cucumber S. hermanni and S. vastus was measured from the extracted GAGs using the Blyscan ${ }^{\mathrm{TM}}$ sulfated GAG assay according to the manufacturer's instructions. The yield of total sulfated GAG (stock concentrations) from the $S$. hermanni $\left(32.03 \pm 6.72 \mu \mathrm{g} \mathrm{mL}^{-1}\right)$ and $S$. vastus $(33.37 \pm 3.87)$ integumental tissue was diluted to $1 \mu \mathrm{g} \mathrm{mL}^{-1}$ and used as test substances in wound healing study. Dilutions were made fresh on the day of assay or stored at $-20^{\circ} \mathrm{C}$.

Experimental animals: Healthy female Sprague-dawley rats weighing 160-180 g (9-11 weeks old) were used in this study and were acclimatized for at least 5 days before the wound study started. The rats were housed individually in clean cages with $12 \mathrm{~h}$ light-dark cycle and provided with food and water ad libitum. The animal house facilities were maintained accordance with Laboratory Animal Research Unit, Universiti Sains Malaysia Health Campus (LARU USM) guidelines. The study was approved by the Animal Ethics Committee Universiti Sains Malaysia.

Full-thickness excisional wound model: The rats were divided randomly into 3 groups of 6 rats each in which two groups were assigned as treatment groups for total sulfated GAG from $S$. hermanni and $S$. vastus integumental tissue and another group was assigned as control (normal buffer saline, PBS). Rats were anesthetized using intramuscular ketamine (90 $\mathrm{mg} \mathrm{kg}^{-1}$ ) and xylazine $\left(5 \mathrm{mg} \mathrm{kg}^{-1}\right.$ ) and their dorsal were shaved and wiped with $70 \%$ alcohol swab followed by povidoneiodine solution. Unilateral standardized $6 \mathrm{~mm}$ (diameter) full-thickness excisional wound was created on the rats dorsal using standardized sterile biopsy punch (Stiefel, USA). Daily treatment of $20 \mu \mathrm{L}$ of $1 \mu \mathrm{g} \mathrm{mL} \mathrm{m}^{-1}$ concentration of total sulfated GAG from the $S$. hermanni and $S$. vastus integumental tissue was applied topically to each rat started from day 0-12 (treatment group).

Wound contraction rate measurements: For evaluation of wound healing, the excision wound and its diameter ( $\mathrm{mm}$ ) was observed and recorded on day 1, 6 and 12 for each treatment and control group of rats (McLennan et al., 2008). The wound diameter ( $\mathrm{mm}$ ) was measured by standard caliper measurement. The wound image was captured by Samsung L100 8.2 megapixels camera. Then wound contraction percentage was calculated according below formula (Sardari et al., 2006).

Percentage of wound contraction $(\%)=\frac{\left(\mathrm{A}_{\text {Day } 0}-\mathrm{A}_{\text {Day } \mathrm{X}}\right)}{\left(\mathrm{A}_{\text {Day } 0}\right)} \times 100$

$$
\left(\text { Day }_{x}=\text { Day } 1 ; 6 ; 12\right)
$$

Statistical analysis: Statistical analysis of the data was performed using a standard software package (Statistical Package for Social Sciences (SPSS) version 12.0.1). The statistical difference between the sulfated GAGs treated groups and control group of wound healing was calculated by using One-way ANOVA and $\mathrm{p}<0.05$ was considered significant. Results were expressed as mean \pm SEM.

\section{RESULTS AND DISCUSSION}

The excision wound diameter was evaluated on day 1, 6 and 12 and shown in Fig. 1. On day 1, it shows that the wound contraction event has started immediately in both sulfated GAG treated group while for the control group, the wound look more vivid and the contraction process not even started. The wound area showed greatly contracted in the treatment groups on day 6 compared to control group. On day 12 , the wound appear smaller and almost not to be seen in the treatment group as the contraction rate progress well while the wound in control group still not fully closed. 

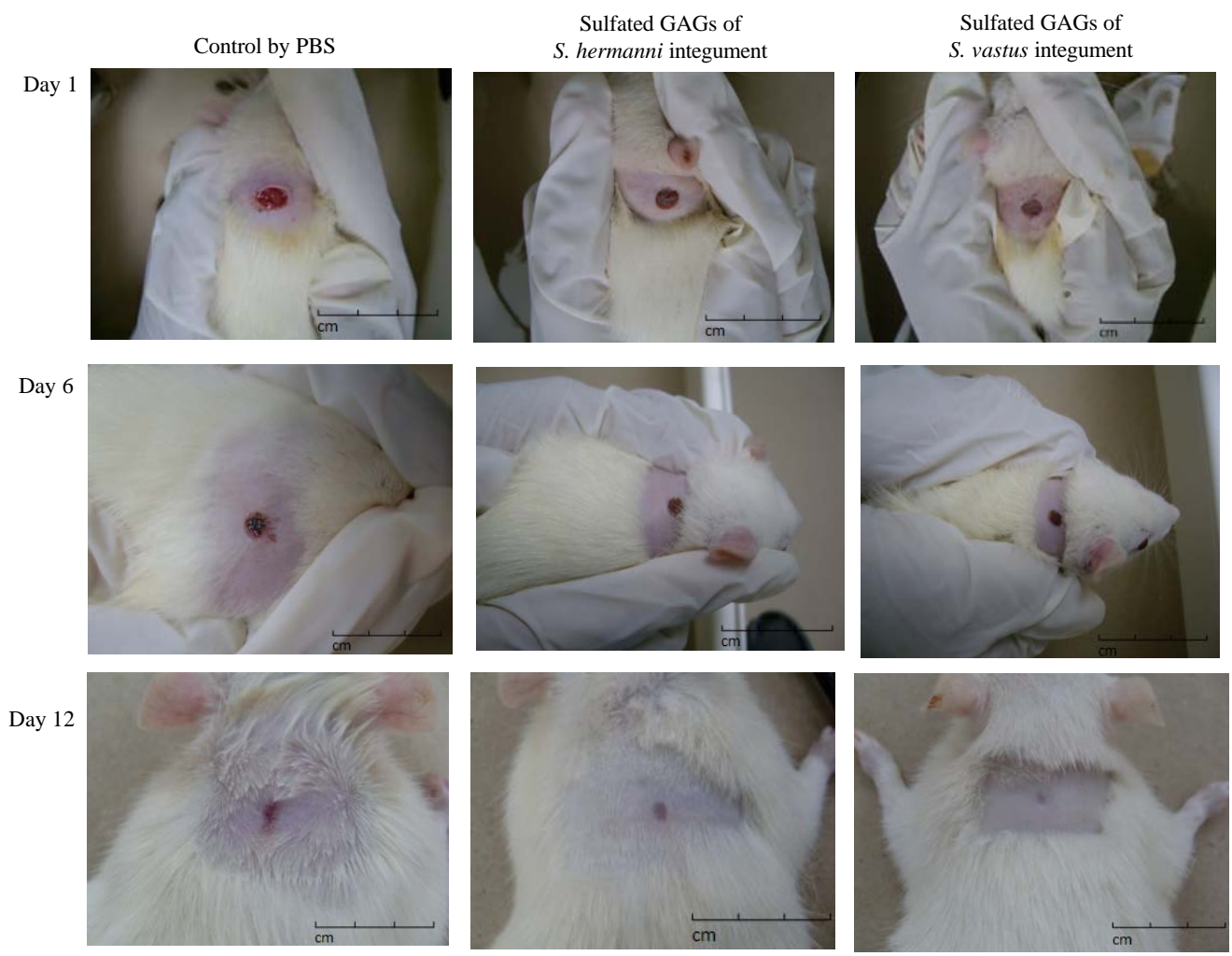

Fig. 1: Macroscopical images of the excision wound healing on day 1,6 and 12 for treatment groups (sulfated GAGs from $S$. hermanni and $S$. vastus integument) and control group (PBS) on rat model

Table 1: Comparison of wound contraction percentage (\%) on day 1, day 6 and day 12 between treatment and control group

\begin{tabular}{|c|c|c|c|}
\hline Day & Groups & Mean \pm SEM & $p^{*}$ \\
\hline \multirow[t]{3}{*}{ Day 1} & Control group (PBS) & $0.00 \pm 0.00$ & \multirow[t]{3}{*}{$<0.05$} \\
\hline & Sulfated GAGs from $S$. hermanni integument & $1.39 \pm 0.88$ & \\
\hline & Sulfated GAGs from $S$ vastus integument & $4.17 \pm 1.52$ & \\
\hline \multirow[t]{3}{*}{ Day 6} & Control group (PBS) & $10.42 \pm 2.08$ & \multirow[t]{3}{*}{$<0.05$} \\
\hline & Sulfated GAGs from $S$. hermanni integument & $24.30 \pm 1.99$ & \\
\hline & Sulfated GAGs from $S$. vastus integument & $31.94 \pm 1.39$ & \\
\hline \multirow[t]{3}{*}{ Day 12} & Control group (PBS) & $55.56 \pm 4.12$ & \multirow[t]{3}{*}{$<0.05$} \\
\hline & Sulfated GAGs from $S$. hermanni integument & $65.28 \pm 2.56$ & \\
\hline & Sulfated GAGs from $S$. vastus integument & $70.14 \pm 1.28$ & \\
\hline
\end{tabular}

*Kruskal Wallis test, $\mathrm{p}<0.05$ as significant at $95 \%$ CI Post-hoc test (LSD) showed significant differences: Day 1: Treatment group from sulfated GAGs of $S$. vastus integument and control group (PBS), $\mathrm{p}=0.03$, Day 6: Treatment group from sulfated GAGs of $S$. hermanni integument and $S$. vastus integument, $\mathrm{p}=0.01$, Treatment group from sulfated GAGs of $S$. hermanni integument and control group (PBS), $\mathrm{p}=0.001$, Treatment group from sulfated GAGs of $S$. vastus integument and control group (PBS), $\mathrm{p}=0.001$, Day 12: Treatment group from sulfated GAGs of $S$. hermanni integument and control group (PBS), $\mathrm{p}=0.03$, Treatment group from sulfated GAGs of $S$. vastus integument and control group (PBS), $p=0.003$

Wound contraction percentage (\%) was calculated at the timed intervals (day 1,6 and 12) as the percentage of wound area that had healed. Table 1 shows the wound contraction percentage $(\%)$ of control and treatment groupson day 1,6 and 12 . The present study showed that the total sulfated GAG from $S$. hermanni and $S$. vastus integument accelerates the wound contraction to heal significantly $(\mathrm{p}<0.05)$ in each time interval compared to control.

Variety approaches for using natural products as new remedies have been explored for both acute and chronic wounds over the past decade. Although, some people view these ideas as somewhat primitive or ignorant many of the remedies are the result of thousands of years of empiric observation. These remedies have their roots in the ancient civilizations of the East as well as those of the Native American and Native South American cultures (Davis and Perez, 2009). Several natural products from marine invertebrates have been reported to promote the process of wound healing (Pujol et al., 2007). Although, many natural products have claimed to have healing effects, most do not have well-controlled scientific data to back their claims. 
There is still lacking of scientific research regarding medicinal potential of sulfated GAGs especially from the local Malaysia sea cucumber, S. hermanni and S. vastus species. Sulfated GAGs have shown various chemical and biological functions that are benefits to human and even living organisms (Toshihiko et al., 2003). In this study, results indicate that sulfated GAGs from the integumental tissue of both sea cucumbers species play a significant contribution for wound healing, through acceleration of wound contraction rate. The process of wound contraction is an important event in wound healing phase being particularly as a major contributor to the healing of a full thickness open wound (Gupta and Lawrence, 2008). This study seem to confirmed that sulfated GAGs act as a promoter of wound healing which have been demonstrated by significant shrinkage of the wound via the treated sulfated GAGs especially from sea cucumber $S$. vastus integument compared to the control group started from day 1 observation. This data supported the previous study that had done on in vitro model where the wound closure rate progress to $92.7 \%$ after $18 \mathrm{~h}$ in the presence of chondroitin sulfate which is one of the sulfated GAGs compound (Zou et al., 2004).

\section{CONCLUSION}

This study has shown that total sulfated GAG from $S$. hermanni and $S$. vastus integument significantly accelerate wound healing compared to control by the enhancement of wound contraction rate.

\section{ACKNOWLEDGEMENTS}

The researchers greatly appreciate Universiti Sains Malaysia for providing the short term research grant (304/PPSK/6139058) to carry out this study. Support and help from Ms. Koo Chuay Yeng and Mr. Abdul Razak Hamzahare also gratefully acknowledged.

\section{REFERENCES}

Annika, N.A., A.B. Hinke-Multhaupt and R.C. John, 2007. Syndecans in wound healing, inflammation and vascular biology. Int. J. Biochem. Cell Biol., 39: 505-528.

Bello, Y.M. and T.J. Phillips, 2000. Recent advances in wound healing. JAMA, 283: 716-718.

Casu, B. and U. Lindahl, 2001. Structure and biological interactions of heparin and heparan sulfate. Adv. Carbohydr. Chem. Biochem., 57: 159-206.
Davis, S.C. and R. Perez, 2009. Cosmeceuticals and natural products: Wound healing. Clin. Dermatol., 27: 502-506.

Frank, S. and H. Kampfer, 2005. Excisional Wound Healing: An Experimental Approach. In: Wound Healing Methods and Protocols, Dipetroand, L.A. and A.L. Burns (Eds.). Human Press, New Jersey, pp: $1-15$.

Gupta, S. and W.T. Lawrence, 2008. Wound Healing: Normal and Abnormal Mechanisms and Closure and Closure Techniques. In: The Physiologic Basis of Surgery, O'Leary, J.P. and A. Tabuenca (Eds.). 4th Edn., Lippincott Williams and Wilkins, USA.

Inkinen, K., 2003. Connective tissue formation in wound healing: An experimental study. Academic Thesis, Faculty of science, University of Helsinki.

Jackson, R.L., S.J. Busch and A.D. Cardin, 1991. Glycosaminoglycans: Molecular properties, protein interactions and role in physiological processes. Physiol. Rev., 71: 481-539.

Kimata, K., O. Habuchi, H. Habuchiand and H. Watanabe, 2007. Knockout Mice and Proteoglycans. In: Comprehensive Glycoscience, Kamerling, J.P. and G.J. Boons (Eds.). Elsevier, Amsterdam, The Netherlands, pp: 159-191.

Ledin, J., W. Staatz, J.P. Li, M. Gotte, S. Selleck, L. Kjellenand and D. Spillmann, 2004. Heparan sulfate structure in mice with genetically modified heparan sulfate production. J. Biol. Chem., 279: 42732-42741.

Liu, H.H., W.C. Koand and M.L. Hu, 2002. Hypolipidemic effect of glycosaminoglycans from the sea cucumber Metriatylascabra in rats fed a cholesterol-supplemented diet. J. Agric. Food Chem., 50: 3602-3606.

McLennan, S.V., J. Bonner, S. Milne, L. Lo and A. Charlton et al., 2008. The anti-inflammatory agent Propolis improves wound healing in a rodent model of experimental diabetes. Wound Rep. Reg., 16: 706-713.

Neha, S.G. and L.M. Ricardo, 2008. The structure of glycosaminoglycans and their interactions with proteins. Chem. Biol. Drug Des., 72: 455-482.

Pujol, C.A., M.J. Carlucci, M.C. Matulewicz and E.B. Damonte, 2007. Natural sulfated polysaccharides for the prevention and control of viral infections. Topics Heterocyclic Chem., 11: 259-281.

Sardari, K., M.M. Dehgan, M. Mohri, M.R. Emami and A. Mirshahi et al., 2006. Macroscopic aspects of wound healing (contraction and epithelialisation) after topical administration of allicin in dogs. Comp. Clin. Pathol., 15: 231-235. 
Staatz, W.D., H. Toyoda, A. Kinoshita-Toyoda, K. Chhorand and S.B. Selleck, 2001. Analysis of Proteoglycans and Glycosaminoglycans from Drosophila. In: Methods in Molecular Biology, Proteoglycan Protocols, Iozzo, R.V. (Ed.). Humana Press Inc., Totowa, NJ USA., pp: 41-52.
Toshihiko, T., C. Amornrut and R.J. Linhardt, 2003. Structure and bioactivity of sulfated polysaccharides. Trends Glycosci. Glyc., 15: 29-46.

Zou, X.H., W.C. Foong, T. Cao, B.H. Bay, H.W. Ouyang and G.W. Yip, 2004. Chondroitin sulfate in palatale wound healing. J. Den. Res., 83: 880-885. 